\title{
Structuring Markets for Resilient Farming Systems
}

\author{
Vivian Valencia $^{1,2}\left(\mathbb{D} \cdot\right.$ Hannah Wittman $^{3} \cdot$ Jennifer Blesh $^{1}$
}

Accepted: 11 March 2019 / Published online: 1 April 2019

(C) The Author(s) 2019

\begin{abstract}
Diversified farms have received considerable attention for their potential to contribute to environmentally sustainable, resilient, and socially just food systems. In response, some governments are building new forms of public support for social-ecological services through the creation of mediated markets, such as targeted public food procurement programs. Here, we examine the relationship between farmer participation in Brazil's National School Feeding Program and farm diversification and household autonomy, as key indicators of farm household resilience. We hypothesized that two key features of the food procurement program - structured demand for diversified food products, and a price premium for certified organic and agroecological production - would increase farm-level agrobiodiversity and the use of agroecological practices. We designed a comparative study between family farmers who do, and do not, participate in Brazil's National School Feeding Program in the plateau region of Santa Catarina in Southern Brazil. We used semi-structured surveys to collect data on farm agrobiodiversity, management practices, and farm household autonomy, and we conducted land use history assessments. Here, we suggest for the first time that the National School Feeding Program played a role in driving the following: (1) transitions on family farms from low agrobiodiversity, input-intensive farming systems to diversified farming systems (i.e., horticultural production) and (2) a significant increase in the cropped area under diversified farming systems. This transition was supported by making horticultural production an economically viable alternative to field crops typically linked to volatile, unpredictable markets. The convergence of public policies supporting mediated markets, increased farm household autonomy, and farm diversification represents an integrated mechanism with the potential to enhance food system resilience.
\end{abstract}

Keywords Agrobiodiversity $\cdot$ Autonomy $\cdot$ Brazil $\cdot$ Diversified farms $\cdot$ Ecosystem management $\cdot$ Public procurement $\cdot$ PNAE

\section{Introduction}

Diversified farming systems have received considerable attention for their potential to contribute to more environmentally sustainable and socially just food systems that are resilient to global change. Diversified farms can support greater biodiversity and multiple ecosystem functions such as soil nutrient cycling and enhanced nutrient retention, pest control, and

Vivian Valencia

v.valencia@wur.nl

1 School for Environment and Sustainability, University of Michigan, Ann Arbor, MI 48109, USA

2 Farming Systems Ecology Group, Wageningen University and Research, Wageningen, The Netherlands

3 Centre for Sustainable Food Systems and Institute for Resources, Environment and Sustainability, The University of British Columbia, 179-2357 Main Mall, Vancouver, BC V6T 1Z4, Canada carbon sequestration (Power 2010). Many diversified farms incorporate agroecological practices, exemplified by the use of ecological principles to inform management of plant diversity for ecosystem function, reducing or eliminating external inputs. Increasing plant diversity at farm and landscape scales, together with use of agroecological practices, can also reduce farmers' vulnerability to social and environmental variabilities by reducing the need for non-renewable inputs (Elser et al. 2014) and contributing to food and nutritional security (Frison et al. 2011). Despite growing evidence for their ecological and social advantages, diversified farming systems have received minimal public and private investments (Kremen and Miles 2012; DeLonge et al. 2015). As such, new analytical approaches are needed to assess food system interventions and policies that address the linked dynamics of food security and ecological sustainability (Wittman et al. 2016).

Current market conditions, especially the consolidation of the global agri-food industry combined with a predominance of policies that favor industrialized agriculture, make it difficult for family farmers to thrive by maintaining diversified 
farming systems (Kremen et al. 2012). In response, governments have developed new forms of public support for socialecological services through targeted public food procurement programs. Social-ecological services are the products and benefits derived from interactions between people and nature in social-ecological systems (Reyers et al. 2013). Public procurement generates a "mediated market" that facilitates family farmers' preferential access to institutional markets for food produced under desired conditions (e.g., local, organic) (Wittman and Blesh 2015; Guerra et al. 2017). Policies that create structured demand-i.e., large-scale, predictable demand generated by public or non-profit institutional food procurement - for a range of nutritious foods (e.g., vegetables, fruits, legumes, dairy) may promote diversified farming systems by increasing their economic viability, while also supporting food and nutrition security (Nehring et al. 2017). Structured demand has received considerable attention for its potential to contribute to food security by reducing risks and vulnerabilities through increased productivity and ensuring reliable food supplies (IPC-IG 2013). Important sources of structured demand for agricultural products include schools, hospitals, food reserves, the military, and food aid programs, such as the United Nations World Food Program's Purchase for Progress initiative (WFP 2015).

Building on the need to identify policy designs that enhance food system resilience by supporting both food security and biodiversity (Wittman et al. 2016), this study advances a novel framework to examine relationships between participation in a specific public food procurement program, the Brazilian National School Meal Program (PNAE, by its Portuguese acronym), farm diversification, and household autonomy as key factors theorized to support farming system resilience. We assess farm diversification by measuring changes in agrobiodiversity - the diversity in crop and livestock varieties and species - as well as the area of farmland under diversified production. We then assess relationships between farm diversification and indicators of household autonomy (e.g., household dietary quality and external input intensity). Autonomy is an important household characteristic that confers resilience by shielding farmers from market shocks and uncertainties through greater reliance on their farms' own productive resources (e.g., land, ecological processes, and knowledge).

We hypothesize that two key features of PNAE, structured demand for diversified food products and a price premium for certified organic and agroecological production, will increase farm-level agrobiodiversity and the use of agroecological practices. Farm diversification, in turn, may support farm household autonomy through two primary mechanisms: (1) sustaining and enhancing ecosystem processes and functions (e.g., soil nutrient cycling, pest control) on farms, thus reducing the need to purchase agricultural inputs, and (2) supporting food and nutritional security through greater consumption of foods from the farm and increased dietary quality (Jones et al. 2014). We focus on dietary quality because it is an important domain of food security that is understudied compared to caloric sufficiency or undernutrition. Overall, our hypothesis is that participation in targeted food procurement programs will increase farm diversification and household autonomy (Fig. 1). When aggregated at the landscape/regional level, farm diversification can build food system resilience to global change by supporting autonomy and thus increasing the viability of farm households that provide critical social and ecological functions.

Finally, we expect that the effects of public food procurement on farm diversification might not be evenly distributed within and among farms. For example, the effects of public procurement may also be affected by farm size. Previous research in our study area showed that farm size influences farmer decisions to participate in PNAE (Guerra et al. 2017). Furthermore, as a result of PNAE's market preference for fruit and vegetable crops, diversification may occur in some farm fields (e.g., horticultural plots where vegetables and fruits are cultivated), while in other fields (e.g., corn, soybeans, and other crops not directly consumed by households) "businessas-usual" management practices involving low diversity and intensive input use may remain. In the following sections, we further elaborate the conceptual linkages between public procurement, farm diversification, household autonomy, and food system resilience. We then describe the case of PNAE in Brazil in more detail and report on relationships between farmer participation in Brazil's National School Feeding Program (PNAE) in Southern Brazil and farm diversification and household autonomy.

\subsection{Farm diversification and food system resilience}

Food system resilience refers to the capacity of food systems (e.g., the network of activities connecting people to their food, operating at multiple scales) to cope with shocks and external pressures and to sustain production of sufficient nutritious, culturally acceptable, and accessible food over time and space (Schipanski et al. 2016). Farm diversification may foster resilient farm households by maintaining a diversity of organisms and functional traits that allow agroecosystems to sustain functions following disturbance (e.g., pest outbreaks; price fluctuations) (Matson et al. 1997; Wood et al. 2015). Diversity of organismal traits occurs across ecological (e.g., genetic, taxonomic diversity), spatial (e.g., agroforestry), and/ or temporal (e.g., crop rotation) scales, and may contribute to maintaining and regenerating biotic interactions that support production and other ecosystem functions. Farm diversification exists along a continuum, but often includes agroecological management practices such as increased crop rotation complexity, cover cropping (i.e., use of non-harvested crops), use of organic nutrient sources such as legumes or manure, 


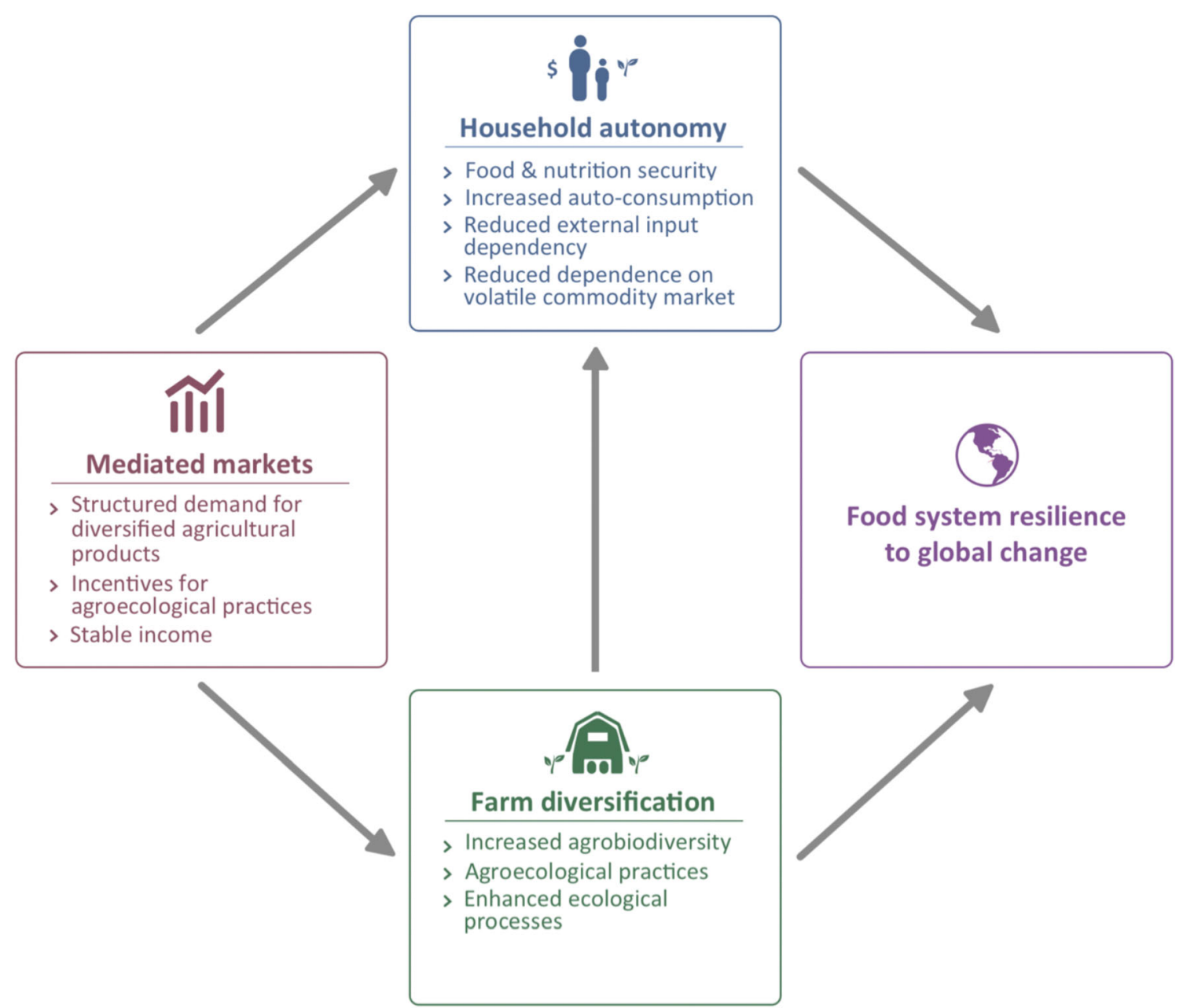

Fig. 1 Conceptual framework articulating the hypothesis that mediated markets support farm diversification and household autonomy, which ultimately enhance food system resilience to global environmental change

and biological control (Iverson et al. 2014). Particular functional groups of crops, such as legume cover crops and perennials, increase functional diversity with plant traits that supply and retain nutrients and increase soil organic carbon storage (Blesh 2017). At larger scales, farm diversification can also reduce agriculture's contribution to global change by reducing external input dependency and associated greenhouse gas emissions. Although processes of farm diversification are managed at the plot and farm (i.e., farming household) scales, the aggregate effect of a network of diversified farms at landscape levels supports resilience in the food system.

Farm diversification also contributes to resilient food systems that deliver improved nutrition and diet outcomes at multiple scales. At the household scale, diversified farming systems can support dietary diversity among family farmers in the context of a changing global nutrition landscape (Berti and Jones 2013). By supporting higher levels of agrobiodiversity, diversified farming systems may increase dietary quality by increasing a farm household's dietary diversity (Jones et al. 2014), or through income generation to purchase foods (Sibhatu et al. 2015). Dietary diversity is of central importance to food and nutrition security, and it is often used as a proxy of dietary quality because more diverse diets are positively associated with the nutrient quality of diets (Jones et al. 2013). Poor dietary quality is leading to the socalled "dual burden of malnutrition," a public health issue characterized by the coexistence of nutrient deficiencies along with overweight and obesity (Rivera et al. 2004), particularly in middle-income countries such as Brazil. At the landscape/ community scale, a higher abundance of diversified farms contributes to food system resilience through positive effects on the nutritional security of non-farming populations by increasing access to diversified foods for the local population (Remans et al. 2015).

\subsection{Household autonomy and resilience to global change}

Farmers are able to navigate shocks and opportunities by relying more on self-provisioning when markets are adverse, 
and by balancing self-provisioning with market-oriented production when crop prices are high (Henderson 2017). Access to markets in which farmers have more control over production and marketing decisions supports self-determination and stability (together comprising autonomy) at the householdlevel, and revitalization of the family farming sector more broadly (Schneider and Niederle 2010). Autonomy is a particularly important household characteristic because it enables resilience to key vulnerabilities related to mainstream markets (e.g., concentrated global production centers, unpredictability) and production systems (e.g., agricultural intensification and homogenization) while increasing farmers' capacity to adapt to shocks and pressures. Autonomy is also present at higher levels of social and spatial aggregations, such as collective engagements (e.g., farmer cooperatives) (van der Ploeg 2008). For example, alternative marketing networks and farmers' associations can enable transitions towards agroecological practices (Stock et al. 2014; Guerra et al. 2017).

Autonomy at farm and community levels is supported by strategies such as food self-provisioning; internalization of resources (e.g., reduced reliance on external inputs); building markets for local foods and alternative networks of commerce; and strengthening and expanding producer control over productive decisions and value chain integration (Schneider and Niederle 2010; Wittman and Blesh 2015). In the past, selfprovisioning was equated with poverty and subsistence, and what was perceived by some as the incapacity of family farmers to modernize. In contrast, current framings recognize self-provisioning as a core element of autonomy and sustainable livelihoods, which has emerged as a form of resistance to - or resilience against - the industrialization of farming and the mainstream food industry (van der Ploeg 2008). These strategies enhance farmers' control over production and marketing decisions, increasing the likelihood these decisions will support viable livelihoods.

\subsection{Public procurement and mediated markets: a pathway to food system resilience?}

Our study examined how targeted public food procurement programs, such as PNAE, may foster farm diversification and household autonomy, as part of a transition to more resilient food systems, through strategies including adoption of agroecological management approaches, support of regionally organized food systems, and increasing access to healthy and culturally relevant food (Schipanski et al. 2016). Specifically, our study examined whether the structured demand generated by public procurement drives cropping system diversification and increases autonomy on family farms. The theory of change proposes that food procurement programs offer (1) demand for diversified food products (e.g., vegetables, legumes, dairy); (2) a reliable source of income generation by creating favorable market conditions for family farmers; (3) price stabilization through establishment and negotiation of prices; and (4) predictable and reliable demand for agricultural products that reduces risks and uncertainties associated with commodity markets (Sumberg and Sabates-Wheeler 2011; Nehring et al. 2017). These four characteristics make it less risky and more profitable for farmers to produce a diverse range of products for local and regional markets (Sumberg and Sabates-Wheeler 2011). Stable and predictable market access for family farmers also strengthens local and regional markets, which can benefit food security and resilience by increasing access to local foods and improving dietary quality.

A substantial body of research has focused on evaluating outcomes of public food procurement for food beneficiaries, but effects on the farms and households of participating family farmers remain understudied. Recent case studies of food procurement programs in Brazil observed two key changes in family farming practices: an increase in agrobiodiversity and a transition towards agroecological management (Blesh and Wittman 2015; Chappell et al. 2016; Guerra et al. 2017). Public procurement programs that offer a $30 \%$ price premium for organic certification may drive, at least partially, transitions to agroecological management practices. Furthermore, causality has not been sufficiently addressed to date. As a result, it is not known whether public procurement for diversified food products drives farm diversification, or whether diversified farms are more likely to respond to procurement calls (a case of selection bias). As such, is important to better understand the process of farm diversification and whether (1) the structured demand generated through public food procurement programs drives changes in agrobiodiversity and other management practices at the farm-level, which would be more likely to impact broader environmental sustainability outcomes; or (2) diversification occurs at the sub-farm level in the plots where the food crops of interest to the public procurement program are grown. Finally, how these changes in cropping systems affect household autonomy remains uncertain.

\subsubsection{Brazil's School Feeding Program (PNAE)}

School feeding programs based on targeted public food procurement aim to increase children's consumption of locally and regionally procured food. The focus on locally produced food reflects increasing understanding of the benefits to farmers, traders, and consumers that can be derived from more localized procurement strategies (Sumberg and SabatesWheeler 2011). Brazil's National School Feeding Program (Programa Nacional de Alimentação Escolar, PNAE) is a globally lauded public procurement program that links objectives in food security, education, and rural development. PNAE originated in the 1950s as a school meal program, but since 2009 has been substantially redesigned. PNAE is now part of a broader food security strategy based on the creation 
of new markets driven by public procurement (Schneider et al. 2016). The success of PNAE in reducing child malnutrition, increasing access to healthy foods, improving eating habits, and reducing school absenteeism has inspired many countries in Latin America and Africa to replicate and adapt its strategies (FAO 2014). Since 2009, PNAE has provided a premium for certified organic and agroecological products (up to $30 \%$ price premium) and priority in contracts for certified production. The PNAE also committed to investing at least $30 \%$ of its budget in purchasing from local family farmers. Here, "local" refers to the municipal scale, where family farmers supply food for the schools in their own municipalities. The establishment of a budget benchmark for expenditures on family farmers, and a premium for organic products, created a unique market for diversified food and agricultural products for family farmers. In this way, PNAE is a form of public investment in a broader suite of social-ecological services from farms.

\section{Materials and methods}

\subsection{Study area}

The study took place over a 6-month period in 2016 in the municipalities of Curitibanos, Correa Pinto, and São Jose do Cerrito in the plateau region of Santa Catarina (SC) state in southern Brazil. In the study municipalities, elevation ranges between 850 and $1050 \mathrm{~m}$ above sea level and terrain is characterized by a hilly, moderately rugged topography. Santa Catarina contains fragments of the Atlantic Forest, restricted to less than $10 \%$ of its original range, mostly scattered in small patches in protected areas and on farmers' properties.

Family farmers in the south generally have more favorable conditions for agriculture compared with other regions of Brazil, including greater access to agricultural credit and infrastructure (Medina et al. 2015). Western SC is also home to one of the largest agro-industrial complexes and meat processing plants for poultry and pig productions in South America. The study municipalities have a broad range of farming systems including soybean, garlic, bean, and corn monocultures; livestock production (e.g., chickens, pigs, dairies); and diversified horticultural crops for both household and market purposes (Fig. 2).

Santa Catarina is one of the states where PNAE has most successfully met its food procurement objectives. For instance, it exceeds the minimum $30 \%$ commitment to procuring food from family farmers (Schneider et al. 2016), with $42 \%$ of its funding for food procurement channeled to family farmers (FNDE 2014). The success of PNAE in SC is recognized by the United Nations Food and Agriculture Organization, who took a delegation of Latin American and Caribbean representatives to SC from the departments of education, health, and agriculture to learn best practices in the
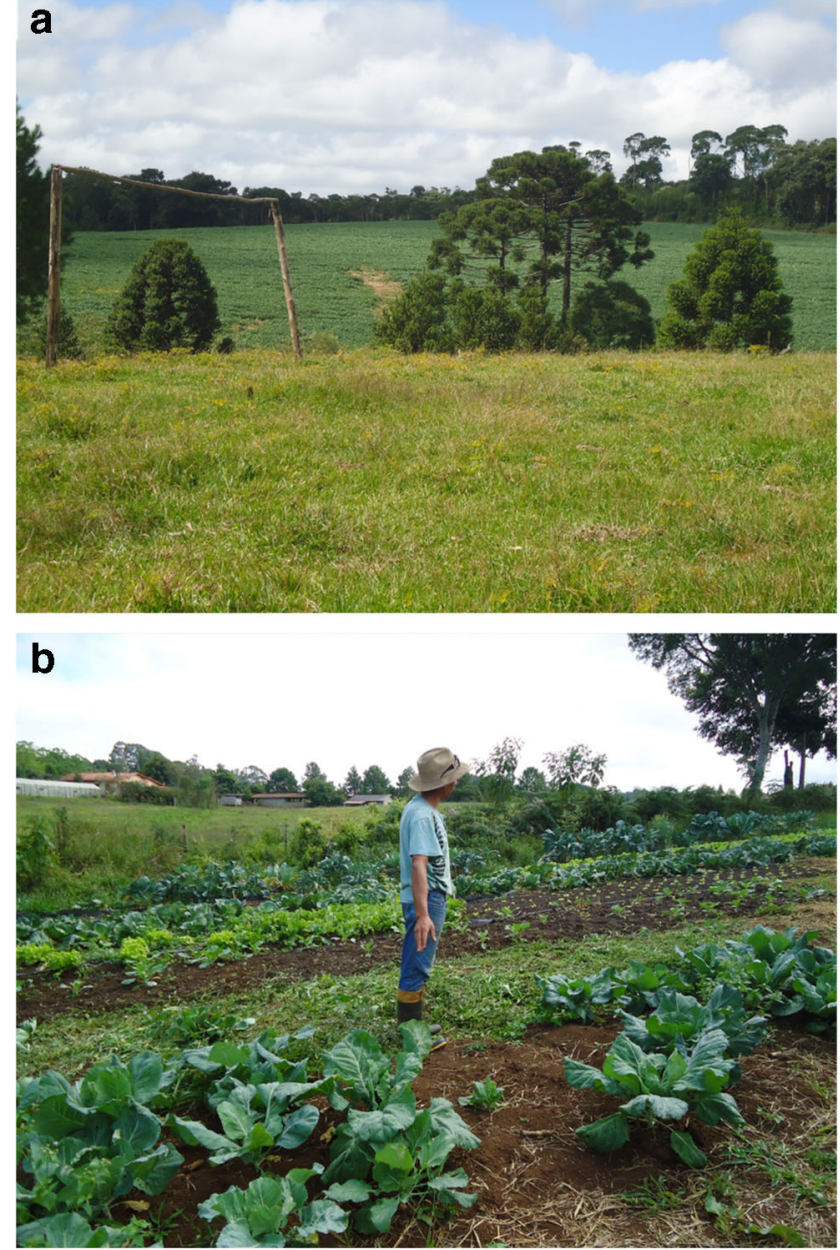

Fig. 2 Contrasting family farming systems in southern Brazil. Farm a: Soybean monoculture and pastureland. Farm b: diversified farming system

design and implementation of lunch programs based on targeted public food procurement programs (FAO 2014). As such, the robust nature of the PNAE policy implementation in SC makes it an ideal study site to conduct an integrated analysis of its impacts in relation to diversification and resilience.

\subsection{Methods and data analysis}

To investigate the effects of PNAE on diversification, autonomy, and resilience, we compared farms from the same communities who were participating in PNAE (treatment group) with farms not participating in PNAE (control group). Family farmer participants were selected to represent the diversity of cropping systems present in the region, and to minimize variation in other variables across farms (e.g., soil and climatic variability).

We interviewed 75 farmers, with PNAE farmers as "treatment" $(n=20)$ and farmers with similar production systems but not participating in the PNAE as "control" $(n=55)$. The 20 sampled PNAE participant farms represented almost $80 \%$ 
of farms participating in the PNAE in study municipalities. On some occasions, multiple farmers from the same household were officially registered as individual PNAE participants, when in fact they were managing the same farming unit. We did not "double count" these farmers as they were managing one farm. This resulted in a smaller sample size of farms involved in PNAE than the total number of farmers officially registered.

Semi-structured household surveys on farms consisted of two sections: one on farm characteristics and management directed to the head of household responsible for farm management (usually, a male farmer), and a second section on dietary diversity directed to the person in charge of meal preparations (in all cases, the female head of household). In a few cases, female heads of households were in charge of farm management and answered both survey sections. Both surveys were conducted simultaneously in farmers' households in Portuguese by the first author and a team of local field assistants and lasted between 60 and $90 \mathrm{~min}$.

Farm management surveys were combined with field assessments to collect data on farm agrobiodiversity (i.e., an inventory of crop species planted in the most recent growing season, and livestock and their abundance); farming practices such as use of cover crops (non-harvested crops), use and type of agrochemical inputs, and source of inputs (i.e., purchased, acquired off the farm, or obtained from farm); extent of mechanization (e.g., use of different irrigation technologies and tractors); farm-level characteristics such as total property size, area in different land use types (e.g., forest, pasture, annual crops), and size of each crop field; markets where each product was sold, such as PNAE, farmers' markets, and intermediaries; and, access to credit and extension services.

We conducted a land use history assessment as part of the farm management survey to identify the effects of PNAE on the process of farming system diversification. We focused on whether farming households had transitioned due to the market demand created by PNAE from a primary economic focus on one cropping system to a different one (e.g., from corn and bean cultivation to horticulture), or from off-farm employment to farming. By primary economic focus, we refer to the primary market-oriented agricultural activity that is the main source of income, in contrast to other agricultural activities that may be practiced solely for household or animal consumption, or secondary agricultural activities that generate supplementary income. We were interested in changes around the time PNAE was established in this region; therefore, we focused on land use changes that occurred during the last three decades. This timeframe includes the onset of PNAE in the last decade, plus a period of time before onset. We also inquired about the reasons and incentives that prompted land use transitions, and specifically focused on the role that PNAE played, if any.

The second section of the survey was directed to the female head of household, who is traditionally in charge of meal preparation in rural areas in Brazil. This section collected data on dietary diversity (described in Section 2.4) and on the sources of each food item consumed (i.e., own farm, farmers' market, supermarket, gift from neighbor or family member).

Finally, we also conducted key informant interviews in SC with community leaders in the family farmers' union, the state agricultural extension service (EPAGRI), a farmers' credit cooperative (CRESOL), and a local NGO (Centro Vianei) that supports agroecology-related projects in the region. Other key informant interviews that provided valuable context were conducted in western SC, outside of study municipalities. The semi-structured informant interviews were key in understanding the study context and interpreting results.

\subsection{Calculation of indicators of diversification}

We assessed farm diversification by measuring agrobiodiversity - the diversity in crop and livestock varieties and species - as well as by capturing the process of farm diversification. This enabled our analysis to capture changes in farm configuration through space (e.g., increase in the area of diversified farming systems) and time (e.g., transition from low to high agrobiodiversity systems).

\subsubsection{Agrobiodiversity}

We calculated four different measures of agrobiodiversity based on species richness and diversity. Using multiple measures allowed us to capture the complexity of agrobiodiversity at the farm and plot (e.g., horticulture) levels. We used a measure of species richness, which is based on simple counts of different cultivated species and varieties and livestock, and the Shannon Diversity index, which considers species' relative abundance. We calculated species richness for all food species (plants and livestock combined) at the farm scale; horticultural crop richness; livestock species richness; and livestock species Shannon Diversity. Plant species and varieties included fruit trees, vegetables, tubers, and legume grains; livestock species include cows, pigs, chickens, turkeys, rabbits, etc. We used the package Biodiversity. $\mathrm{R}$ in the statistical software $\mathrm{R}$ to calculate these metrics (Kindt and Coe 2005).

\subsubsection{Farm diversification process}

The process of farm diversification was captured by two analyses: (1) land use history assessments that indicate transitions in the primary economic activity from low agrobiodiversity systems, such as corn and bean monocultures, to horticulture systems, and (2) increases in the total area of diversified farming systems, namely horticulture plots. Together, these analyses capture the process of farm diversification occurring through time and space. 


\subsection{Autonomy at the farm household scale: food self-provisioning, dietary quality, and external input intensity}

We operationalized the concept of autonomy by using indicators that focused on food self-provisioning and internalization of resources. These indicators captured the degree to which farmers make production decisions on their farms, and their degree of dependency on external inputs and resources associated with the industrial food system. For food self-provisioning, we combined an indicator of the proportion of food consumed from a farm's own production, with an indicator of dietary diversity. This combined measure is a proxy for household dietary quality, capturing the extent to which farmers rely on their own production for household consumption needs, and qualifying the resulting diet to highlight the importance of access to nutritious food. We calculated food selfprovisioning by assessing the proportion of food items consumed in the last $24 \mathrm{~h}$ that were obtained from a household's own production. For consistency, we used the same 24-h recall data that was used to calculate the Household Dietary Diversity Score.

We assessed the quality of dietary intake by calculating dietary diversity indicators according to the Household Dietary Diversity Score (HDDS) (Swindale and Bilinsky 2006) and the Food Consumption Score (FCS) as proxies of dietary diversity (WFP 2007). The HDDS was developed as a measure of household food access, defined as the ability to acquire a sufficient quality and quantity of food to meet all household members' nutritional requirements for a productive life (Swindale and Bilinsky 2006). Similarly, the FCS is also informed by linkages between dietary diversity and household food access, and is thus useful in monitoring food insecurity (Jones et al. 2013). The HDDS is constructed using data on dietary intake over the previous $24 \mathrm{~h}$ in a household for 12 food groups: cereals, roots and tubers, vegetables, fruits, meat, eggs, fish and seafood, pulses and nuts, milk and milk products, oils and fats, sugar, and condiments. The FCS combines data on dietary diversity and food frequency using a recall period. In this study, the recall period was based on weekly consumption rates over the previous 30 days of eight food groups (i.e., staple grains and tubers, pulses, vegetables, fruits, meat and fish, dairy products, sugar, and oil). The consumption frequency of each food group is multiplied by a predetermined weight, and the resulting values are summed to obtain the FCS for the household.

The external input intensity indicator, based on Garibaldi et al. (2016), was constructed by adding +1 for each input purchased or acquired from off the farm; -1 for each input or organic amendment (e.g., compost, legume cover crops) acquired from the farm based on farmers' own resources; and adding -0.5 for amendments or pest control products made from both internally and externally acquired ingredients. This resulted in a quantitative index which ranged between +7 and -5 to capture a household's use of all externally acquired inputs for farm production (e.g., manure not from own livestock). This metric aligns with the definition of agroecological practices, which seeks to reduce use of off-farm inputs, even those allowed under certified organic production, by managing plant diversity (e.g., cover crops or intercrops), or integrated crop-livestock systems for greater ecological function. Inputs included pesticides, bactericides, herbicides, fungicides, fertilizers, chicken manure, cow manure, cow urine, and composts.

Because diversified farms exist along a management continuum, and synthetic inputs have greater environmental costs than organic inputs (Matson et al. 1997), we also calculated a second index solely considering synthetic/non-organic input use intensity (rather than all purchased inputs). Because we found that synthetic input use intensity was highly correlated with total external input intensity $(r=0.90)$, we only report the latter. Each field or plot may be under different management strategies; thus, the external input intensity index was calculated for individual fields on each farm. We then calculated a farm-scale index by weighting each field's index by the farm's total cropped area.

\subsection{Statistical analyses}

We compared farm-level agrobiodiversity and autonomy between farmers enrolled in PNAE and the control group by conducting Welch two sample $t$ tests and two-sample Wilcoxon tests when data did not meet the assumption of normality. We checked for normality using the Shapiro-Wilk test. Values are reported as significant at $p<0.05$. To test how farm size and PNAE interact to influence a farmer's choice to diversify production, we repeated statistical comparisons stratified by two farm size levels: smaller farms $(<12$ ha, $n=25)$ and larger farms (>12 ha, $n=50$ ).

The land use history data from the household surveys were analyzed by quantifying PNAE farmers' primary economic activity at the time of interview, the percentage that had a different primary economic activity in the past, and what that primary economic activity was. The reasons for transition were documented.

We tested for the effects of agrobiodiversity on household autonomy and dietary diversity for the entire sample $(n=75)$. We then conducted two separate regression analyses with the external input intensity index as the dependent variable, and each regression with one metric of agrobiodiversity (either total food species richness or horticulture plot richness) as the independent variable. We also conducted two sets of separate regression analyses, each set with one of the two measures of dietary diversity (HDDS and FCS) as the dependent variable and a different measure of agrobiodiversity (either total food species richness or horticulture richness) as the 
independent variable. Because agrobiodiversity may support dietary diversity by generating income for purchasing food, we repeated 12 additional linear regression analyses: six with HDDS as the dependent variable and the other six with FCS as the dependent variable. For each analysis, we used one of six different proxies for household income as the independent variable: total area cropped, number of cattle, and area planted to either garlic, soybean, bean, or horticultural crops.

\section{Results and discussion}

\subsection{Farm characteristics}

Farm characteristics such as farm size, size of horticultural fields, and proportion of farm in perennial species (e.g., grass, trees) and annual crops (e.g., corn, soybean) differed between farmers in PNAE and the control group (Table 1). On average, PNAE farmers had smaller farms (3 to 34 ha) with a smaller proportion of their farm planted in annual field crops. The size of horticultural plots (and vegetable production as a proportion of total cropped area) was, on average, much larger than that of farms in the control group. In addition to selling vegetables and diversified agricultural products to PNAE, many farmers $(65 \%)$ also sold vegetables in the local farmers' market. Production areas for field crops, such as beans, corn, and soybean, were on average smaller for PNAE farmers ( $p$ value $<0.05)$.

\subsection{Farm diversification}

\subsubsection{Effects of PNAE on agrobiodiversity}

In our study sample, in addition to cultivating at least one field crop, most farmers cultivated a horticultural plot (ranging from small home gardens to larger, market-oriented plots) (96\%), fruit trees (100\%), and at least one type of livestock (e.g., chicken, pigs) for household consumption (99\%). Among the PNAE farmers $(n=20)$, vegetable production was the primary market-oriented agricultural activity. PNAE farmers also cultivated corn $(n=8)$ and beans $(n=11)$, either for household and animal consumption or as a secondary income-generating activity; in the study area, neither corn nor beans were generally delivered to PNAE. To a lesser extent, PNAE farmers cultivated garlic $(n=2)$ and soybean $(n=$ 1 ) as a complementary income-generating activity. Among farmers not involved with PNAE $(n=55)$, primary marketoriented activities included dairy farming $(n=15)$, garlic $(n=12)$, soybean $(n=11)$, vegetable crops $(n=10)$, and beans $(n=7)$. Many farmers in the control group cultivated both soybean and garlic $(n=10)$. Most farmers cultivated corn $(n=43)$ to feed their own animals and to sell directly to neighbors or intermediaries.

Farms involved in PNAE had higher agrobiodiversity compared to the control group for measures related to total food species richness on farms, and horticultural plot richness $(p$ value < 0.01) (Fig. 3). When we repeated the analysis stratified by farm size, among smaller farms $(<12$ ha), agrobiodiversity tended to be higher, but the difference was no longer statistically significant between groups. Nonetheless, the average size of horticulture plots was twice as large for smaller-scale PNAE farmers than for the control group ( $p$ value $<0.01$ ). Even though the absolute land area in vegetable production tended to be small ( $0.1-0.4 \mathrm{ha})$, this corresponded to a large difference in the proportion of total cropped area in horticultural production: $66 \%$ for PNAE farmers compared with $28 \%$ in the control group ( $p$ value $<0.05$ ).

Among larger farms (>12 ha), involvement with PNAE resulted in significantly higher farm-scale food species richness ( $p$ value $<0.05$ ) and a more than doubling of horticultural plot richness $(p<0.001)$. The size of the horticulture plot tripled ( $p$ value $<0.001$ ), which corresponded to $45 \%$ of the cropped area in horticulture, on average, among PNAE farmers versus $4 \%$ in the control group ( $p$ value $<0.001$ ). There were no differences in livestock richness between farmers involved with PNAE and the control group (irrespective of farm size); only livestock Shannon diversity was slightly higher for the control group ( $p$ value $<0.05$ ).
Table 1 Mean farm characteristics for farmers involved in PNAE vs. control group

\begin{tabular}{lccc}
\hline & PNAE farmers & Control group & $p$ value \\
\hline Farm size (ha) & $11.6(8.3)$ & $41.4(45.3)$ & $* * *$ \\
Horticultural crops (ha) & $0.3(0.2)$ & $0.1(0.3)$ & $* * *$ \\
Proportion (\%) of cropped area in horticultural crops & $56.5(43)$ & $10(24.7)$ & $* * *$ \\
Proportion (\%) in annual crops & $13.9(17.9)$ & $33.9(26.2)$ & $* * *$ \\
Proportion (\%) in perennial crops & $86.1(17.9)$ & $66.1(26.2)$ & $* * *$ \\
\hline Standard deviation in parentheses & & & \\
$* * * p$ value $<0.001$ & & & \\
$* * p$ value $<0.01$ & & & \\
$* p$ value $<0.05$ & & &
\end{tabular}




\section{Food crops and livestock}

\section{Richness}

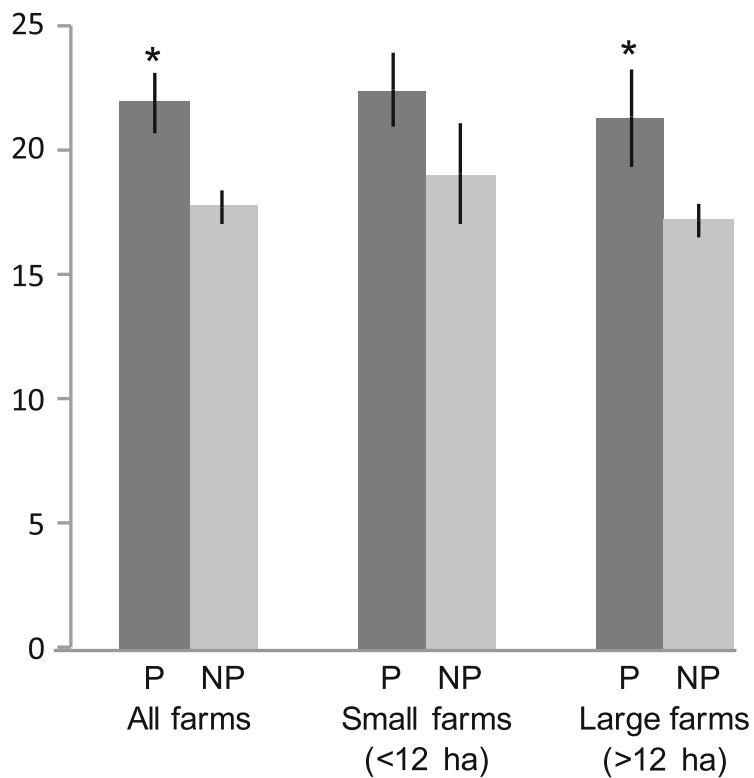

\section{Richness}

\section{Horticulture}

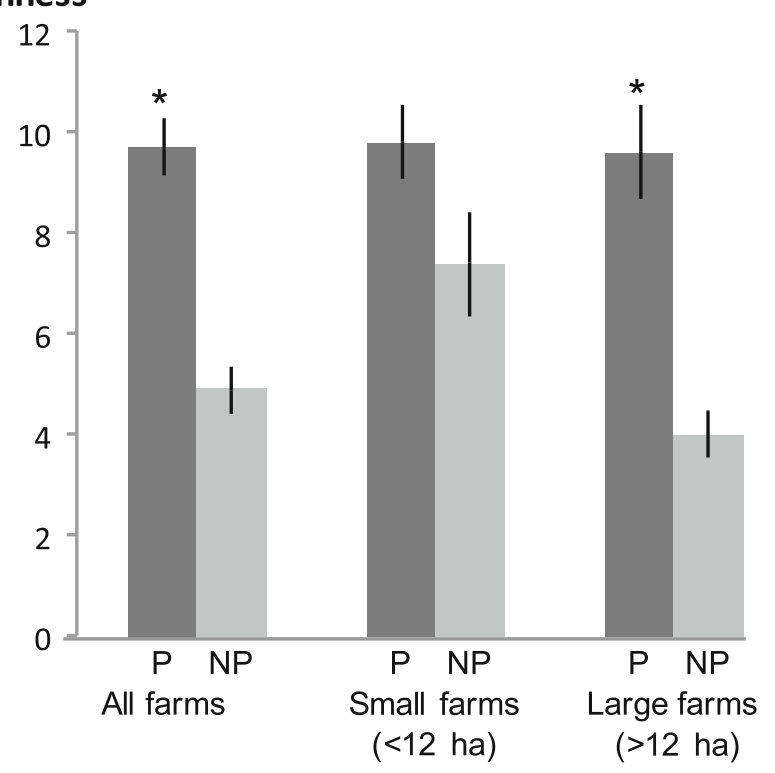

Fig. 3 Mean farm-level agrobiodiversity measures for food crop and animal richness (top) and horticulture plot richness (bottom) for farmers involved in PNAE (P) vs. the control group (non-PNAE, NP) for all farms combined, and stratified by small vs. large farms. An asterisk denotes $p$ value $<0.05$. Bars represent standard error

\subsubsection{Effects of PNAE on the process of farm diversification}

Land use history assessments at the time of interview revealed that the primary economic activity for $95 \%$ of PNAE farmers was vegetable production. Prior to their involvement with PNAE, most farmers in the PNAE group (80\%) had a different agricultural activity as their main economic focus: more than half of the farmers $(55 \%)$ previously cultivated corn and beans, either in monocrops or intercropped systems; other farmers' (25\%) main focus was either garlic or soybean production in input intensive monocrop systems; and for a few farmers (20\%), it was employment in urban areas or as farm workers. When we stratified the analysis by farm size within the PNAE group, we found the same pattern in land use change trajectories.

Data from farmer interviews showed that participation in PNAE played a direct role in farmers' decisions to shift their household's primary economic focus from low agrobiodiversity, input-intensive farming systems to more diversified, low external input systems. Once PNAE emerged as an easily accessible and stable market for vegetables, many farmers expanded the area of their vegetable plots from small home gardens for household consumption to market-oriented plots.

Farmers explained that this shift was incentivized by guaranteed purchases leading to a reliable monthly income distributed over the school year, and by the stability and accessibility of the market generated by PNAE. For a subset of PNAE farmers $(20 \%)$ - who, prior to enrollment with PNAE, were already market-oriented horticultural producers - the price premium offered by PNAE for certified agroecological cultivation incentivized a transition to organic production practices. Local NGOs and farmers' associations were fundamental in supporting participation in PNAE and a transition to agroecological practices (see also Guerra et al. 2017). Farmers explained that the reason for this transition was that horticultural production for PNAE had lower production costs (e.g., lower or no costs for agrochemical inputs; lower labor requirements) and land requirements (i.e., higher profits per unit area) than did commercial gain cultivation (corn, beans, soybeans).

\subsection{Autonomy}

\subsubsection{Household food self-provisioning and dietary diversity}

There were no statistically significant differences in food selfprovisioning between PNAE and non-PNAE farmers; both groups obtained, on average, half of their food from their own farms (Fig. 4). When we disaggregated food selfprovisioning by certain food groups, between PNAE and control farmers, we found that the mean proportion of food selfprovisioning for vegetables was higher for PNAE farmers ( $80 \%$ vs. $58 \%, p$ value $<0.01$ ), although that for meat was lower ( $35 \%$ vs. $59 \%, p$ value $<0.05$ ), possibly because nonPNAE farmers have higher mean animal abundance (54 vs. $65, p$ value $<0.05$ )

The effect of PNAE on food self-provisioning varied between the two farm size groups: on smaller farms $(<12$ ha), there was no significant difference in food self-provisioning 

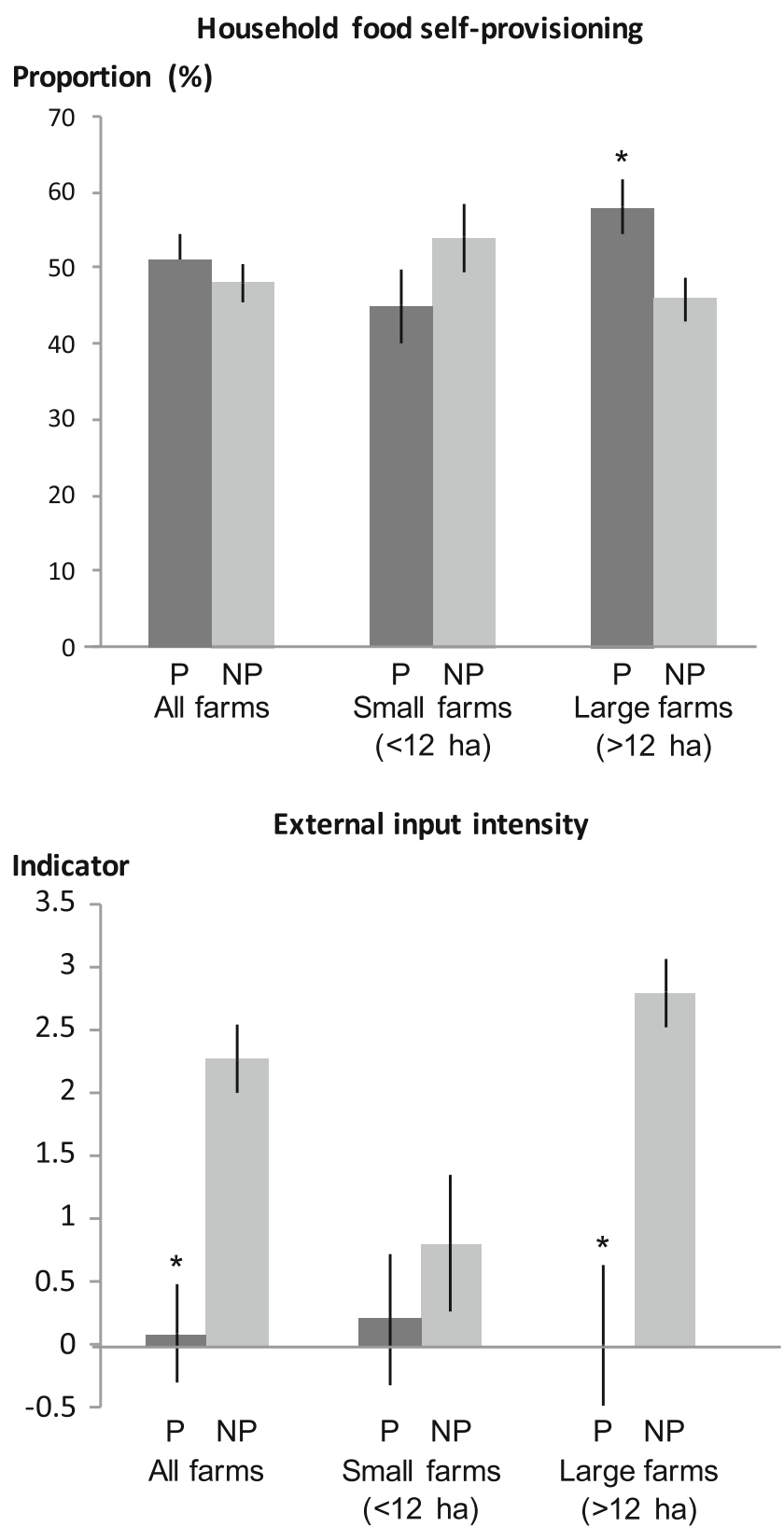

Fig. 4 Mean household food self-provisioning (top) and external input intensity (bottom) on farms involved in PNAE (P) vs. control group (nonPNAE, NP) for all farms and stratified by small and large farms. Asterisk denotes $p$ value $<0.05$. Bars represent standard error

between PNAE and the control groups, but for larger farms (> $12 \mathrm{ha}$ ), food self-provisioning was greater among PNAE farmers $(p$ value $<0.05)$ (Fig. 4). On smaller farms ( $<12$ ha), food self-provisioning of vegetables and meat was not significantly different between the two groups ( $p$ value $>0.05$ ). For larger farms ( $>12 \mathrm{ha}$ ), food self-provisioning of vegetables was significantly greater for PNAE farmers $(96 \%$ vs. $49 \%, p$ value $<0.0001$ ), but there was no difference for meat.

Overall, family farmers in this region, regardless of their participation in PNAE, relied on food self-provisioning as an important strategy to meet their household consumption needs. This is congruent with similar findings that show production for own consumption has gained ground in southern Brazil (Schneider and Niederle 2010), although it contradicts other findings that show that industrialized family farmersthe typical farmers found in our control group - have decreased reliance on food self-provisioning (Sacco dos Anjos et al. 2010). Consuming food produced on the farm helps to buffer against market variability, granting farmers autonomy over their own food, producing non-monetary income, and supporting food security (Schneider and Niederle 2010). These results show that food self-provisioning is not an obsolete strategy and that it does not necessarily have to disappear as farmers become market-oriented or specialized. Instead, policy- and decision-makers should recognize this strategy as an important mechanism to simultaneously support food security and ecosystem services.

Across all farms, total food species richness was a significant, but weak predictor of dietary diversity as measured by the HDDS $\left(R^{2}=0.06 ; p\right.$ value $\left.<0.05\right)$. None of the other measures of agrobiodiversity, or proxies for household income, were significant predictors of dietary diversity. There were no differences in measures of dietary diversity between farmers involved with PNAE and the control group, regardless of farm size.

Food species richness as a predictor of dietary diversity is congruent with other studies (Jones et al. 2014). However, the fact that we were unable to detect differences in dietary quality between PNAE and non-PNAE farmers does not necessarily mean there were no important differences in dietary quality between the two groups. Instead, this may indicate that the dietary diversity metrics used here are not suited to a relatively developed rural area in a middle-income country where household socioeconomic characteristics are relatively high (Ruel 2003). There is a need for better metrics and methods to test the relationship between production diversity and dietary diversity that are also relevant to middle-income countries.

\subsubsection{External input intensity}

Higher levels of agrobiodiversity (both food and horticultural crop richness at the farm level) were associated with lower external input intensity ( $p$ value $<0.01$ ). We also found that PNAE farmers had much lower external input intensity than the control group ( $p$ value $<0.001$ ). However, when disaggregated by farm size, external input intensity was not significantly different for PNAE and control groups for small farms ( $<12$ ha), while among larger farms $(>12$ ha), external input intensity was much lower for PNAE farms $(p$ value $<0.05)$ (Fig. 4). We repeated this analysis separately for each cropping system type on farms. We found no differences in external input intensity for horticultural crops (irrespective of farm size); however, external input intensity was much lower 
for corn $(p$ value $<0.01)$ and beans $(p$ value $<0.001)$ for farmers involved in PNAE, but among small farms $(<$ 12 ha), the difference was not statistically significant.

More work is needed to better understand the links between biodiversity, ecosystem functions, and the reduced input dependency measured here. Presumably, greater agrobiodiversity alongside use of ecological practices enhanced ecological processes such as soil organic matter accumulation, trophic interactions that control pests and diseases, or nutrient supply through biological nitrogen fixation or decomposition, but measuring changes in these processes was outside of the scope of this study. Future research should also focus on understanding other metrics of diversity, such as plant functional traits, and their relationship to ecosystem functions. We also found evidence that largerscale PNAE farms had significantly more land area in perennial crops (e.g., trees, animal forage) and a reduced proportion of the farm in annual field crops, which is another key indicator of farm-scale sustainability (Liebman et al. 2013). Yet, elucidating mechanistic relationships between farm-scale functional diversity and ecosystem services remains a critical research need (Wood et al. 2015), which could inform improvements to farm management and to agri-environmental policy schemes.

\subsection{Building food system resilience}

Diversification is a key mechanism for enhancing food system resilience, but diversified systems face significant challenges in terms of policy support, market access, and research and development. Public support to generate greater socialecological services from farms is needed for resilient food systems that expand the distribution of nutritious foods to a wider population. In particular, targeted public food procurement is an underexplored policy instrument capable of addressing some of the complex problems related to food system resilience and food insecurity. In this form of market, the state mediates relationships between supply (family farms) and demand (food security and public nutrition programs) (Wittman and Blesh 2015). The PNAE program in Brazil exemplifies how the strategic use of public procurement may align efforts across multiple sectors (agriculture, public health and nutrition, and education) to respond to the need for policies that build resilience in both rural economies and food systems in the context of global environmental change.

Our study showed that public support through PNAE increased the diversity and autonomy of farms, but the effects of PNAE on these outcomes were moderated by farm size. For small farms, the main contribution of PNAE was enabling farmers to transition a greater area of their cultivated land to diversified horticulture for regional markets. On larger farms, PNAE had a greater effect, increasing overall agrobiodiversity as well as the proportion of land area in horticultural production for regional markets, while also increasing household consumption of vegetables produced on the farm, and reducing the use of external inputs. This is consistent with other research showing that farm size affects production patterns and decision-making, because smaller- and larger-scale farms have differential capacities to capture economies of scale and make investments in equipment and other resources. For example, as farms grow in size, crops that are more suitably grown in small plots (e.g., vegetables) are reduced as a percentage of total farm area, whereas field crops that can be cultivated with mechanized techniques (e.g., cereal crops) are maintained or increased (Herrero et al. 2017).

One of the unique contributions of our study was showing the significant role that PNAE played among participating farms in driving an increase in the area of diversified cropping systems: overall, the proportion of a farm's cropped area covered by horticulture was fourfold greater on PNAE farms than on non-PNAE farms. This increase supports farmers' livelihoods as well as the production of diverse foods for markets. Supporting production of diversified crops is particularly important given the homogenization of the food supply towards a few staple crops such as corn, wheat, and rice (Khoury et al. 2014). As such, this form of public procurement program responds to growing calls for mechanisms to sustain and enhance smallholders' contributions to production diversity and hence to the overall dietary diversity of the world's population (Fanzo 2017).

Our analyses showed that farms enrolled in PNAE were characterized by higher agrobiodiversity and lower reliance on external inputs; however, we cannot attribute these effects solely to PNAE. For instance, we found that differences in horticultural richness, household food self-provisioning, and external input intensity between PNAE and non-PNAE farmers were all more pronounced on larger PNAE farms (> 12 ha). However, overall, PNAE was more appealing to the relatively smaller farms $(<12$ ha) for whom vegetable cultivation is preferable in terms of returns per unit area and labor requirements. Larger-scale farmers who focused on production of commodity crops such as soybean did not generally seek integration into the mediated market for local foods created by PNAE, even if they also maintained small, low-input horticultural plots for household consumption. Although other variables were not included in the analysis that could have influenced farmers' management decisions (e.g., membership in farmer organizations), we find these results to be consistent with the literature (e.g., Herrero et al. 2017). PNAE is therefore strategic for allowing smaller farms to transition to diversified farming systems and remain economically viable while supporting their contribution to local food and nutrition security.

At the same time, we found that PNAE may currently have limited reach in terms of off-farm environmental impacts as a program that primarily targets procurement of vegetable and fruit crops. That is, PNAE does not necessarily provide a sufficient incentive to transform management practices for 
the entire farm or for all cropping system types. In spite of the increase in diversified production on PNAE farms, the absolute area of diversified cropping systems is relatively small compared to total farm size, and management practices in the other cropping systems that occupy more land-usually monocrops managed with agrochemical inputs-in many cases remained unaffected by PNAE. For example, both agroecological and input-intensive systems often continued to co-exist within farms (e.g., a conventionally managed corn plot alongside an ecologically managed horticultural plot). Plot level differences in management practices across different cropping systems also speak to a more nuanced effect of PNAE (Guerra et al. 2017). For example, the external input intensity indicator for horticultural plots was not different between PNAE and non-PNAE farmers, regardless of farm scale. This means that many farmers were already managing their vegetable plots in low-input, high agrobiodiversity systems. On the other hand, external input use intensity for corn and beans was lower for PNAE compared to non-PNAE farmers (statistically significant among larger-scale family farmers). We argue that these differences are likely not the direct result of PNAE, but rather a secondary effect. Farmers in PNAE are often also involved in workshops by local NGOs and are in contact with extension agents who promote agroecological practices; in contrast, soybean and garlic farmers regularly receive technical assistance associated with the sale of agrochemical inputs and seeds. It is through this channel that PNAE's impacts on management may eventually extend to the whole farm and help realize broader environmental sustainability goals. This study suggests that increases in the production of social (e.g., improve farmers' livelihoods) and nutritional (e.g., increasing production of diversified foods) services are currently the most important effects of PNAE.

\subsection{PNAE: supporting strategies for autonomy via market integration and farm diversification}

PNAE contributed to autonomy by supporting farmer integration into a mediated market for local foods and alternative networks of commerce. PNAE operates under different terms than commodity markets: it offers stable and predictable demand and prices. The resulting reduction in market risks granted farmers greater control over household decisions regarding land use, management, and the value chain. PNAE also contributed to household autonomy by allowing farmers to maintain or transition to diversified farming systems as their main economic activity. The autonomy fostered by market integration and management based on self-provisioning reduced farmers' vulnerability to unpredictable markets (e.g., fluctuations in prices, unreliable demand and buyers, market shocks) while enhancing their resilience to regional and global environmental change.
Southern Brazil is characterized by higher infrastructure development, access to credit and resources, and economic development relative to other regions in Brazil (Medina et al. 2015). This means that we cannot assume that the success of PNAE in the south (e.g., FAO 2014) may be equally replicated in other regions. The use of public procurement as a policy instrument to drive food system sustainability in other developing regions of the world should consider access to infrastructure and resources as potential mediating factors in the success of this type of public policy. Moreover, in this region of Brazil, growing diversified food products for household consumption - along with its management knowledgeexisted before the onset of PNAE. In regions where home gardens are not part of local traditions - and hence local knowledge on growing diversified foods may be absentfarmers may face additional limitations in responding to targeted procurement programs such as PNAE.

Finally, one may argue that farmers involved in PNAE have displaced their dependency from the commodity market to an institutional market, which has in recent decades been less volatile and risky than commodity markets. This creates a different type of vulnerability for participating farmers because they now depend on this commercialization channel. If the PNAE was to be terminated, the autonomy of farmers and the continuity of diversified farming systems may be jeopardized. This is one reason why diversification of nonagricultural activities - or pluriactivity - is also an important strategy to build resilience in farming households (van der Ploeg 2008).

\section{Conclusion}

Diversified farming systems have the potential to contribute to environmentally sustainable and socially just systems that may buffer against global change (Kremen et al. 2012; Schipanski et al. 2016); however, mainstream markets and dominant agricultural policies make it difficult for diversified and small-scale farmers to thrive. To understand the role of public support for social and ecological servicesthrough the creation of public procurement programs that support diversified farming systems-we focused on Brazil's National School Feeding Program (PNAE), an emblematic example. We examined the effects of farmer participation in PNAE on farm diversification and household autonomy. We found that public policies that create market support for diversified farming systems contribute to food system resilience by enhancing family farmers' autonomy and supporting diversified farming systems. However, this support may have a limited impact on environmental sustainability given that only a limited number of family farmers participate, and the sustainability changes that PNAE brings are focused on vegetable cropping systems 
that take up a small amount of total farm area. Broader impacts for environmental outcomes could depend on whether low input, diversified production for PNAE ends up motivating changes to management on farmers' other cropped fields.

Overall, our study suggests that public procurement contributes to food system resilience through four key strategies. First, PNAE supports diversified farming systems by increasing demand for agrobiodiversity and including incentives for agroecological practices. Second, PNAE creates an economically viable and stable market for diversified agricultural products that is an alternative to volatile, unpredictable commodity markets. Third, public food procurement programs link local producers (family farmers) with local consumers (e.g., procurement beneficiaries) in a process of economic localization. Food system localization as an economic development strategy is emerging as a response to the negative effects of globalization and trade liberalization. Lastly, public procurement increases local and regional access to nutritious food by generating a spill-over effect in which excess horticultural production not sold to PNAE was channeled through local markets. By linking production and consumption at the municipal level, PNAE may strengthen local and regional food systems and increase the availability of diversified, nutritious foods. As such, targeted public food procurement is a promising strategy to foster food system resilience to global environmental change, by simultaneously supporting rural development and food and nutrition security.

Acknowledgments This research was supported by the School for Environment and Sustainability, the Graham Institute, and the Crosby Fellowship at the University of Michigan. The authors thank the farmers who contributed to this study and the logistical support provided by CRESOL, Epagri, and the Farmer's Union in Curitibanos. We would like to thank Dr. Joshua Farley at the University of Vermont, Dr. Zilma Peixe at the Universidade Federal de Santa Catarina in Curitibanos, Dr. Abdon Schmitt at the Universidade Federal de Santa Catarina in Florianopolis, and Centro Vianei for their valuable guidance. The authors are grateful for the support of field assistants Diego Correa, Danilo Macedo, Aleixa de Souza, Kathrine de Souza, Leticia Pereira, and Laura Vezzani. Finally, we thank three anonymous reviewers whose comments greatly improved the manuscript.

Data availability The datasets generated and analyzed during the current study are available from the corresponding author on reasonable request.

\section{Compliance with ethical standards}

\section{Conflict of interest The authors declare no conflict of interest.}

Open Access This article is distributed under the terms of the Creative Commons Attribution 4.0 International License (http:// creativecommons.org/licenses/by/4.0/), which permits unrestricted use, distribution, and reproduction in any medium, provided you give appropriate credit to the original author(s) and the source, provide a link to the Creative Commons license, and indicate if changes were made.

\section{References}

Berti PR, Jones AD (2013) Diversifying food and diets: using agricultural biodiversity to improve nutrition and health, 1st edn. Routledge, London; New York

Blesh J (2017) Functional traits in cover crop mixtures: biological nitrogen fixation and multifunctionality. J Appl Ecol 55:38-48. https:// doi.org/10.1111/1365-2664.13011

Blesh J, Wittman H (2015) "Brasilience:" assessing resilience in land reform settlements in the Brazilian Cerrado. Hum Ecol 43:531-546

Chappell MJ, Moore JR, Heckelman AA (2016) Participation in a city food security program may be linked to higher ant alpha- and betadiversity: an exploratory case from Belo Horizonte, Brazil. Agroecol Sustain Food Syst 40:804-829. https://doi.org/10.1080/21683565. 2016.1160020

DeLonge M, Miles A, Carlisle L (2015) Investing in the transition to sustainable agriculture. Environ Sci Pol 55:266-273. https://doi. org/10.1016/j.envsci.2015.09.013

Elser JJ, Elser TJ, Carpenter SR, Brock WA (2014) Regime shift in fertilizer commodities indicates more turbulence ahead for food security. PLoS One 9:e93998. https://doi.org/10.1371/journal.pone. 0093998

Fanzo J (2017) From big to small: the significance of smallholder farms in the global food system. Lancet Planet Health 1:e15-e16. https://doi. org/10.1016/S2542-5196(17)30011-6

FAO (2014) Scaling up the Brazilian school feeding model: using southsouth cooperation to share Brazil's experience of school feeding in Latin America and the Caribbean. Food and Agriculture Organization, Rome, Italy

Frison EA, Cherfas J, Hodgkin T (2011) Agricultural biodiversity is essential for a sustainable improvement in food and nutrition security. Sustainability 3:238-253

Fundo Nacional de Desenvolvimento da Educação (2014) Aquisições agricultura familiar 2014. [data file]. Retrieved from: http://www. fnde.gov.br/programas/alimentacao-escolar/alimentacao-escolarconsultas/dados-da-agricultura-familiar. Accessed 22 May 2016

Garibaldi LA, Carvalheiro LG, Vaissière BE et al (2016) Mutually beneficial pollinator diversity and crop yield outcomes in small and large farms. Science 351:388-391. https://doi.org/10.1126/science. aac7287

Guerra J, Blesh J, Schmitt A, Wittman H (2017) Pathways to agroecological management through mediated markets in Santa Catarina, Brazil. Elem Sci Anth 5. https://doi.org/10.1525/elementa.248

Henderson TP (2017) Struggles for autonomy from and within the market of southeast Mexico's small coffee producers. J Peasant Stud 0:124. https://doi.org/10.1080/03066150.2017.1382478

Herrero M, Thornton PK, Power B, Bogard JR, Remans R, Fritz S, Gerber JS, Nelson G, See L, Waha K, Watson RA, West PC, Samberg LH, van de Steeg J, Stephenson E, van Wijk M, Havlík $P$ (2017) Farming and the geography of nutrient production for human use: a transdisciplinary analysis. Lancet Planet Health 1(1): e33-e42. https://doi.org/10.1016/S2542-5196(17)30007-4

IPC-IG (2013) Structured demand and smallholder farmers in Brazil: the case of PAA and PNAE. United Nations Development Programme, Brasilia

Iverson AL, Marín LE, Ennis KK, Gonthier DJ, Connor-Barrie BT, Remfert JL, Cardinale BJ, Perfecto I (2014) REVIEW: do polycultures promote win-wins or trade-offs in agricultural ecosystem services? A meta-analysis. J Appl Ecol 51:1593-1602. https:// doi.org/10.1111/1365-2664.12334

Jones AD, Ngure FM, Pelto G, Young SL (2013) What are we assessing when we measure food security? A compendium and review of current metrics. Adv Nutr: Int Rev J 4:481-505

Jones AD, Shrinivas A, Bezner-Kerr R (2014) Farm production diversity is associated with greater household dietary diversity in Malawi: 
findings from nationally representative data. Food Policy 46:1-12. https://doi.org/10.1016/j.foodpol.2014.02.001

Khoury CK, Bjorkman AD, Dempewolf H, Ramirez-Villegas J, Guarino L, Jarvis A, Rieseberg LH, Struik PC (2014) Increasing homogeneity in global food supplies and the implications for food security. Proc Natl Acad Sci 201313490:4001-4006. https://doi.org/10.1073/ pnas. 1313490111

Kindt R, Coe R (2005) Tree diversity analysis. A manual and software for common statistical methods for ecological and biodiversity studies. World Agroforestry Centre (ICRAF), Nairobi, Kenya

Kremen C, Miles A (2012) Ecosystem services in biologically diversified versus conventional farming systems: benefits, externalities, and trade-offs. Ecol Soc 17. https://doi.org/10.5751/ES-05035-170440

Kremen C, Iles A, Bacon C (2012) Diversified farming systems: an agroecological, systems-based alternative to modern industrial agriculture. Ecol Soc 17:288-306. https://doi.org/10.5751/ES-05103170444

Liebman M, Helmers MJ, Schulte LA, Chase CA (2013) Using biodiversity to link agricultural productivity with environmental quality: results from three field experiments in Iowa. Renewable Agric Food Syst 28:115-128. https://doi.org/10.1017/ S1742170512000300

Matson PA, Parton WJ, Power AG, Swift MJ (1997) Agricultural intensification and ecosystem properties. Science 277:504-509. https:// doi.org/10.1126/science.277.5325.504

Medina G, Almeida C, Novaes E, Godar J, Pokorny B (2015) Development conditions for family farming: lessons from Brazil. World Dev 74:386-396. https://doi.org/10.1016/j.worlddev.2015. 05.023

Nehring R, Miranda A, Howe A (2017) Making the case for institutional demand: supporting smallholders through procurement and food assistance programmes. Glob Food Sec 12:96-102. https://doi.org/ 10.1016/j.gfs.2016.09.003

Power AG (2010) Ecosystem services and agriculture: tradeoffs and synergies. Phil Trans R Soc B 365:2959-2971. https://doi.org/10.1098/ rstb. 2010.0143

Remans R, DeClerck FAJ, Kennedy G, Fanzo J (2015) Expanding the view on the production and dietary diversity link: scale, function, and change over time. Proc Natl Acad Sci 112:E6082-E6082. https://doi.org/10.1073/pnas.1518531112

Reyers B, Biggs R, Cumming GS, Elmqvist T, Hejnowicz AP, Polasky S (2013) Getting the measure of ecosystem services: a socialecological approach. Front Ecol Environ John Wiley \& Sons, Ltd 11:268-273. https://doi.org/10.1890/120144

Rivera JA, Barquera S, González-Cossío T, Olaiz G, Sepúlveda J (2004) Nutrition transition in Mexico and in other Latin American countries. Nutr Rev 62:S149-S157

Ruel MT (2003) Is dietary diversity an indicator of food security or dietary quality? A review of measurement issues and research needs. Food Nutr Bull 24:231-232
Sacco dos Anjos F, Velleda Caldas N, Griep Hirai W (2010) Mudanças nas práticas de autoconsumo dos produtores familiares: estudo de caso no sul do brasil. Agroalimentaria 16:115-125

Schipanski ME, MacDonald GK, Rosenzweig S, et al (2016) Realizing resilient food systems. BioScience biw052. https://doi.org/10.1093/ biosci/biw052

Schneider S, Niederle PA (2010) Resistance strategies and diversification of rural livelihoods: the construction of autonomy among Brazilian family farmers. J Peasant Stud 37:379-405. https://doi.org/10.1080/ 03066151003595168

Schneider S, Thies V, Grisa C, Belik W (2016) Potential of public purchases as markets for family farming. In: Barling D (ed) Advances in food security and sustainability. Academic Press, Burlington, pp 69-95

Sibhatu KT, Krishna VV, Qaim M (2015) Production diversity and dietary diversity in smallholder farm households. Proc Natl Acad Sci 112:10657-10662. https://doi.org/10.1073/pnas.1510982112

Stock PV, Forney J, Emery SB, Wittman H (2014) Neoliberal natures on the farm: farmer autonomy and cooperation in comparative perspective. J Rural Stud 36:411-422. https://doi.org/10.1016/j.jrurstud. 2014.06.001

Sumberg J, Sabates-Wheeler R (2011) Linking agricultural development to school feeding in sub-Saharan Africa: theoretical perspectives. Food Policy 36:341-349. https://doi.org/10.1016/j.foodpol.2011. 03.001

Swindale A, Bilinsky P (2006) Household Dietary Diversity Score (HDDS) for measurement of household food access: indicator guide (v.2). Washington, D.C.

van der Ploeg (2008) The new peasantries : struggles for autonomy and sustainability in an era of empire

WFP (2007) Food consumption analysis: calculation and use of the food consumption score in food consumption and food security analysis. World Food Program, Rome

WFP (2015) Purchase for progress. Rome

Wittman H, Blesh J (2015) Food sovereignty and Fome zero: connecting public food procurement programmes to sustainable rural development in Brazil. J Agrar Chang n/a-n/a 17:81-105. https://doi.org/10. 1111/joac. 12131

Wittman H, Chappell MJ, Abson DJ, Kerr RB, Blesh J, Hanspach J, Perfecto I, Fischer J (2016) A social-ecological perspective on harmonizing food security and biodiversity conservation. Reg Environ Chang 17:1-11. https://doi.org/10.1007/s10113-016-1045-9

Wood SA, Karp DS, DeClerck F, Kremen C, Naeem S, Palm CA (2015) Functional traits in agriculture: agrobiodiversity and ecosystem services. Trends Ecol Evol 30:531-539. https://doi.org/10.1016/j.tree. 2015.06.013

Publisher's note Springer Nature remains neutral with regard to jurisdictional claims in published maps and institutional affiliations. 